\title{
UNA MOMIA EN EL SALÓN. LOS MUSEOS ANATÓMICOS DOMÉSTICOS DEL DOCTOR VELASCO (1854-1874)*
}

\author{
Luis Ángel Sánchez Gómez \\ Universidad Complutense \\ langel@ucm.es
}

Recibido: 22 julio 2014; Aceptado: 20 septiembre 2014.

\begin{abstract}
Cómo citar este artículo/Citation: Sánchez Gómez, Luis Ángel (2015), "Una momia en el salón. Los museos anatómicos domésticos del doctor Velasco (1854-1874)", Asclepio, 67 (2): p111. doi: http://dx.doi.org/10.3989/asclepio.2015.29

RESUMEN: El artículo estudia los museos anatómicos organizados por el doctor Pedro González Velasco en dos de sus domicilios particulares en el Madrid decimonónico. Se revisan las circunstancias que hacen posible su creación, vinculadas tanto con el estudio y la docencia de la anatomía como con los proyectos políticos de regeneración y modernización de la Medicina española que trata de poner en marcha su propietario. Se comentan sus singulares colecciones (de anatomía, teratología, zoología, etnografía y curiosidades diversas) y se analiza la proyección docente y sociopolítica de ambos centros, sin cuya existencia no hubiera sido posible que Velasco construyera poco después su gran Museo Antropológico, sede del actual Museo Nacional de Antropología en Madrid.
\end{abstract}

PALABRAS CLAVE: Doctor Velasco; Museo Anatómico; Museo Antropológico; Anatomía; Antropología.

\section{A MUMMY IN THE LIVING ROOM. THE DOMESTIC ANATOMICAL MUSEUMS OF DOCTOR VELASCO (1854-1874)}

ABSTRACT: In this article we examine the two anatomical museums organized by Dr. Pedro González Velasco in his own homes in nineteenth-century Madrid. We analyze the circumstances that made possible the formation of the centers, which were related to the study and teaching of anatomy and to some Velasco's political projects of regeneration and modernization of Spanish Medicine. We explore its collections (of anatomy, teratology, zoology, ethnography and "curiosities") and we try to show how Velasco used his museums with both teaching and sociopolitical objectives. Finally, it is clear that without the formation of these little museums it would not have been possible for Velasco the construction of his great Anthropological Museum, in 1875, which now houses the National Museum of Anthropology.

KEY WORDS: Doctor Velasco, Anatomical Museum, Anthropological Museum, Anatomy, Anthropology.

Copyright: $\odot 2015$ CSIC. Este es un artículo de acceso abierto distribuido bajo los términos de la licencia Creative Commons Attribution-Non Commercial (by-nc) Spain 3.0. 
El médico y cirujano segoviano Pedro González Velasco (1815-1882) es un personaje citado de forma habitual en los estudios sobre historia de la medicina y la antropología en España. Su figura se asocia a tres circunstancias singulares: a un tardío, poco predecible y finalmente vertiginoso éxito profesional; a una personalidad excéntrica y morbosa; y, por último, a la creación en Madrid del Museo Antropológico, sede del actual Museo Nacional de Antropología. Si el acercamiento se hace con algo más de detalle, no dejarán de advertirse otras iniciativas, como la creación de sociedades médicas y antropológicas o la fundación de relevantes publicaciones periódicas de carácter científico. Por el contrario, si el interesado es alguien ajeno a la historia de la ciencia, su atención se focalizará casi exclusivamente en dos temas: el "Gigante extremeño» y la momia de la hija del doctor, ambos ciertamente relevantes en su biografía pero en modo alguno definidores de sus ambiciosos proyectos médicos y antropológicos. En las páginas que siguen estudiaremos un ámbito muy poco conocido de esa ingente actividad: los museos anatómicos que Velasco instala en sus domicilios particulares de la madrileña calle de Atocha entre 1854 y 1874, previos a la construcción del gran Museo Antropológico cuyo edificio aún contemplamos.

\section{LAS COLECCIONES ANATÓMICAS (CIENCIA, EDU- CACIÓN Y NEGOCIO)}

Los afanes coleccionistas de nuestro protagonista echan a andar en fecha temprana ${ }^{1}$. En sus apuntes autobiográficos, González Velasco (1864, p. 7) asegura que ya antes de comenzar sus estudios de Medicina, en el segundo año de los correspondientes a «cirujano de tercera clase» (en 1841-42), dispone de preparaciones y vaciados que usa tanto para su propio estudio como para los "repasos» que comienza a impartir a otros estudiantes. Los ingresos que obtiene con estas clases y el (escaso) sueldo que gana desde agosto de 1845, cuando es ascendido al cargo de "aparatista» en el Hospital Militar de Madrid, son suficientes para que comience a poner en práctica la idea de "conservar y reproducir las preparaciones y disecciones anatómicas para formar un museo» (González Velasco, 1864, p. 9).

En mayo de 1854, con 38 años, Velasco obtiene por fin el doctorado en Medicina, aunque para entonces es ya un reconocido cirujano que disfruta de un nivel de vida envidiable. De hecho, durante los meses de julio y agosto de ese mismo año puede permitirse el lujo de realizar su primer viaje científico por Europa (González Velasco, 1854)². Es durante esta época de éxito profesional, y tras superar no pocas tribulaciones, cuando su prestigio como cirujano y ciertas influencias hacen posible que alcance su primer y casi único triunfo académico, vinculado además de forma directa con sus proyectos museográfico-docentes: en marzo de 1857 el nuevo ministro de Fomento, el progresista Claudio Moyano, le nombra director de los «Museos Anatómicos» de la Facultad de Medicina de la Universidad Central $^{3}$ (veáse figura 1 ).

Velasco asume con entusiasmo esta nueva responsabilidad, que ciertamente resulta muy positiva para la institución. Su interés se centra no tanto en los vaciados como en las «desecaciones» que él mismo prepara, que considera mucho más útiles para la docencia. Gracias a estas colecciones, profesores y estudiantes disponen de unos recursos esenciales para el desarrollo de las prácticas, con los que en buena medida se evitan los problemas asociados a la disponibilidad de cadáveres y a su conservación. No obstante, pese a la intensa actividad que desarrolla (o quizás precisamente por ello), durante los años que permanece al frente del centro los enfrentamientos con autoridades políticas y académicas son recurrentes, y de ello da buena cuenta, con abundantes protestas, lamentos y documentos de descargo, en la memoria de $1864^{4}$. Lo más llamativo del caso es que en este inestable escenario se entremezclan sin pudor intereses públicos y privados: de un lado, la dirección del museo y la enseñanza de la Medicina; de otro, los proyectos empresariales - preparaciones y vaciados - del propio Velasco, que por una u otra razón acaban siendo frustrados (González Velasco, 1864, pp. 38-39). Ante tal cúmulo de contratiempos y dificultades, en mayo de 1864 (cuando está fechada su memoria $)^{5}$ renuncia a la dirección del centro, «porque ya he cumplido mi misión en mi país, que tan mal ha comprendido e interpretado mis trabajos y mis esfuerzos en el trascendental ramo de la anatomía, base de la ciencia médica» (González Velasco, 1864, p. 72).

\section{EL MUSEO DE ATOCHA 135 (1854-1864)}

Pero volvamos atrás. Como el afán coleccionista de Velasco se incrementa según aumentan sus recursos económicos, tres años antes de acceder a la dirección del museo universitario puede hacer realidad la «primera edición» de sus planes museográficos particulares. Nos referimos a la formación de su primer "Museo Anatómico», inaugurado el 9 de noviembre de 1854 en la que por entonces es su residencia familiar en Madrid, en el «cuarto entresuelo de la derecha» del número 135 de la calle de Atocha ${ }^{6}$ (González Velasco, 1854, p. 96). 
Figura 1. Gabinete (museo) Anatómico de la Facultad de Medicina de Madrid (La llustración, 21 de julio de 1849). Las figuras de las vitrinas exentas (y muchas de las restantes piezas) se conservan hoy en el Museo de Anatomía "Javier Puerta", en la Facultad de Medicina de la Universidad Complutense

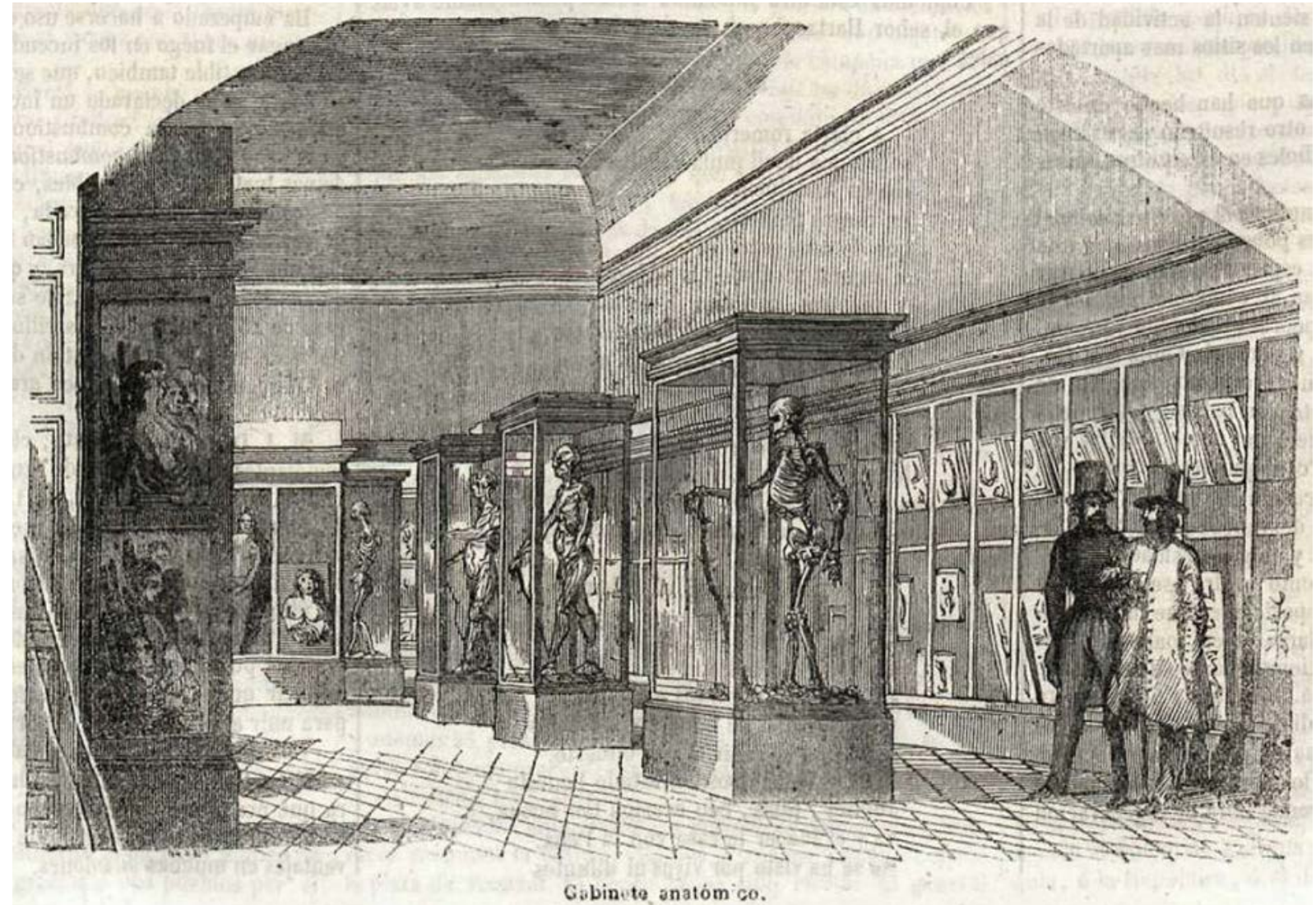

A diferencia de lo que ocurre con su segundo museo, el de Atocha 90, de este proyecto inicial no existe documento gráfico alguno. Sin embargo, sí disponemos de una descripción que el propio doctor adjunta a la primera y más extensa de sus memorias de viaje por Europa, la que edita en 1854. Con la mezcla de pragmatismo y ampulosidad que le caracteriza, asegura haber "aprendido muchas verdades» en su reciente viaje y ser consciente de las tremendas limitaciones que tiene $-\mathrm{y}$ parece que seguirá teniendo- el estudio de la Medicina y la Anatomía en España. Por ello, para mostrar «hasta qué punto podemos llegar por nuestra actividad propia» y para «ilustrar [a] la juventud que puebla las aulas médicas», decide "poner a disposición del público» su Museo Anatómico (González Velasco, 1854, p. 92) (véase figura 2).

¿Qué se muestra en esta primera creación museística velasqueña? En primer lugar, es obvio que el uso del término "museo» responde en parte a intereses propagandistas, a la intención de generar una imagen académica e institucional del centro ante la opinión pública; en realidad, ni su tamaño, ni su estructura, ni su funcionamiento se adecúan a lo que ya a mediados del XIX se considera un verdadero museo. Es cierto, no obstante, que el concepto se usa entonces - como ahora- de forma harto despreocupada, y que sirve para nombrar tanto a instituciones especializadas de gran relevancia histórica y patrimonial como a cualquier colección o conjunto de objetos que se presenta de forma más o menos ordenada para su contemplación. Poco más, y hasta menos, que esto eran muchos museos anatómicos universitarios, sobre todo los españoles, a los que ciertamente supera ya -me refiero a los nacionales - esta primera creación de Velasco. El museo reúne «una sorprendente colección de huesos humanos, comprendiendo desde los primeros rudimentos de la osificación, hasta el completo desarrollo»; le sigue otra con ejemplos reales y modelos de «deformidades, lesiones anatómicas [...], y los vicios generales reumático, sifilítico y escrofuloso»; una "completísima y numerosa reunión de cráneos, entre los que se encuentran varios 


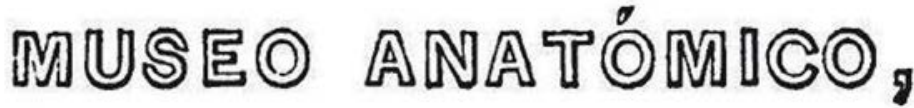

\section{GABINETE DE LECTURA MEDICA}

\author{
I Repasos leórico-práclicos \\ DEL Dr. D. PEDro gOnZalez Velasco, \\ Calle de dotocba, nuim. 135, cuarto entresuelo de la derecba.
}

de criminales, idiotas y monomaniacos»; "fetos de todas edades» y "maniquíes para vendajes y colocación de los mismos» (González Velasco, 1854, pp. 94-95). También incluye materiales que hoy pueden parecer incongruentes pero que a mediados del XIX forman parte de cualquier museo anatómico: la sección de «anatomía comparada», con esqueletos, vísceras y animales disecados. Finalmente, completan la colección otras «muchas curiosidades», cuyo detalle no se especifica. El carácter científico-docente de todo este despliegue se refuerza con "un excelente microscopio», instrumentos quirúrgicos antiguos y modernos, un laboratorio y un "gabinete de lecturas médicas", en el que se pueden consultar los «atlas anatómicos y quirúrgicos de más nota, diccionarios, obras clásicas y periódicos científicos de todas las naciones».

Pese a que Velasco establece unas cuotas para hacer uso (profesional) de su museo, las visitas no parecen ser una fuente de ingresos significativa ${ }^{7}$. Sí lo son sus «repasos», cuyo éxito depende en parte de la singular colección anatómica que ofrece a los estudiantes para el desarrollo de las prácticas. De hecho, la propaganda que hace de su docencia privada destaca la relevancia del instrumental, de la bibliografía médica y, muy especialmente, de los materiales museográficos de que dispone:

Mis colecciones de embriología, también hoy sin rival, recogidas a costa de sacrificios y desvelos en el transcurso de 20 años, como las magníficas de osteo- logía, figuras artificiales y demás objetos que constituyen mi museo, todo a vuestra disposición [énfasis de Velasco], os facilitará el camino de vuestra carrera [...] y os hará entrar con elementos sólidos en la práctica del profesorado ${ }^{8}$.

Obviamente, este primer museo doméstico consolida el prestigio de su propietario. Gracias a un completo despliegue de colecciones anatómicas y anatomopatológicas, Velasco se presenta ante el conjunto de la sociedad $-y$ muy especialmente ante los colegas médicos, los estudiantes y la potencial clientela- no sólo como un extraordinario cirujano, sino como un estudioso de primerísimo nivel, capaz de elevarse muy por encima del acto médico cotidiano y adentrarse en el reservado mundo de la investigación y la sistematización de los conocimientos científicos. También es verdad que la singularidad de sus colecciones, su carácter para algunos macabro, le otorgan un aura de misterio y necrofilia que no hará sino incrementarse con el transcurso de los años ${ }^{9}$.

Por unas u otras razones, y a pesar de sus reducidas dimensiones y al hecho de localizarse en un domicilio privado - lo que, por otra parte, genera más morbola existencia del museo es bien conocida por la gente de la calle, aunque pocos lo hayan visitado. La prensa - tanto la médica como la generalista - se encarga de dar noticia puntual de su evolución, del incremento de las colecciones y de la visita de personajes ilustres. 
Entre estas últimas, sabemos de la realizada por tres «embajadores marroquíes» en septiembre de 1860, que al parecer también habían visitado la Facultad de Medicina ${ }^{10}$. En el museo de Velasco se «maravillan» ante todo lo que allí se exhibe. Por el artículo sabemos que en el centro del salón una vitrina muestra «curiosos y variados objetos [...] de los tres reinos de la naturaleza», muy probablemente rocas, fósiles, algún pequeño animal disecado y quizás incluso alguna curiosidad histórica o arqueológica. También se introducen los visitantes en el despacho del doctor, donde quedan fuertemente impresionados por una «momia embalsamada [...] vestida de blanco», que hace guardia junto al sillón de trabajo de su propietario ${ }^{11}$.

La visita de los ciudadanos marroquíes es tan exótica como exitosa. Sin embargo, mucho más llamativa y en buena medida desconcertante es la que realiza tres años después, el 26 de mayo de 1863, un personaje de especialísimas características: el cardenal arzobispo de Toledo y primado de España, el franciscano P. Cirilo de Alameda Brea ${ }^{12}$. El suelto del católico y ultraconservador diario La España, que informa de tan extraordinario acontecimiento, anota que "Su eminencia se estuvo enterando con suma minuciosidad de cuantos objetos llamaban su atención y dirigió las más halagüeñas alabanzas al entendido profesor que tanto amor manifiesta a los progresos de la ciencia». ¿Cómo fue posible semejante visita? ¿Pretendía el cardenal escenificar un acercamiento entre ciencia y fe? No, indudablemente no ${ }^{13}$. Aunque no se ofrece ninguna información al respecto, podemos presumir que el cardenal acude al doctor como paciente, para ser atendido por uno de los más eminentes cirujanos del momento; por aquellos años, el más famoso de Madrid y probablemente de toda España. El hecho de que Velasco sea públicamente reconocido como progresista, republicano y hasta cierto punto anticlerical -o, quizás mejor, "antifrailuno»- no es obstáculo para que la jerarquía eclesiástica recurra a sus servicios y para que aquél se los proporcione a un precio seguramente acorde a su prestigio.

Como decíamos, también informa la prensa sobre la entrada de nuevas piezas. La mayoría de las incorporaciones procede de la práctica médica del doctor; casi todas son moldes o preparaciones anatómicas de patologías, pero también hay órganos con algún tipo de alteración y numerosos fetos, bien sean sus esqueletos o preservados íntegramente en alcohol. Raro era que Velasco atendiese un parto teratológico, o tuviera noticia del mismo, y que no se hiciera con el feto. Cuando no puede disponer del cadáver, se apresta a elaborar un molde de la patología o del cuerpo completo. El ritmo de entrada de nuevos materiales casi se podría calificar de frenético durante estos primeros años de la década de 1860. Buena prueba de ello -y del tipo de piezas que interesan al doctor - la tenemos en el resumen que hace $E$ I Genio quirúrgico ${ }^{14}$ de las incorporaciones registradas durante 1861: «[...] modelos de elefantiasis ${ }^{15}$, cánceres de todas clases, espinas ventosas enormes ${ }^{16}$, afecciones sifilíticas curiosísimas [...], quistes de todas clases, modelos de hidroceles ${ }^{17}$ y aneurismas confundidos indebidamente con hernias, monstruosidades de fetos y de niños, lo más raro y extraordinario que presentan los anales de la obstetricia, con otra multitud de objetos de historia natural, que para bien de la ciencia y gloria nacional han aumentado la riqueza de este museo».

Como el museo es también un extraordinario escaparate para exhibir los éxitos de su propietario, éste modela en determinados casos la patología que presenta el paciente y el (feliz) resultado de su intervención. Es lo que ocurre, por ejemplo, tras extirpar un enorme "tumor encefaloideo del ojo» en octubre de $1862^{18}$. En otras ocasiones (aunque más en los dos museos posteriores que en este), se hace referencia al ingreso de piezas anatómicas artificiales con las que sus entusiastas creadores pretenden resolver la carencia o pérdida de las originales. Una de las más llamativas es una "cabeza con nariz postiza de plata, tan bien ejecutada y aplicada, tan esbelta en su forma, que cualquiera duda si es artificial o verdadera ${ }^{19}$.

Y, ¿qué ocurre con las colecciones etnográficas? Realmente, apenas sabemos nada sobre la existencia de este tipo de materiales en las vitrinas de Atocha 135 , lo que no significa que no los hubiere. La única información precisa sobre la entrada de una singular pieza exótica es la que documenta la prensa, en septiembre de 1862, relativa al ingreso de "la cabeza de un indio antropófago [...] de un jefe de tribu salvaje $»^{20}$. Se trata de la cabeza reducida de un jíbaro (shuar), una tzantza, que el artículo de prensa describe de forma correcta, anotando también de manera sumaria en qué consiste el proceso de reducción y cuál es el significado simbólico de tan singular pieza.

Al margen de las visitas y de la incorporación de objetos que anota la prensa, disponemos de escasa información sobre el funcionamiento cotidiano del museo. No obstante, sí podemos confirmar que el doctor recurre a algunos de sus más fieles discípulos y colaboradores para desarrollar alguna tarea singularizada en el centro. Así, en octubre de 1861 se cita en la prensa a un «interno del museo anatómico-pato- 
lógico» encargado (seguramente entre otras tareas) de inscribir a los alumnos en sus célebres repasos y cursos de anatomía ${ }^{21}$. Justo un año después se pone nombre al responsable de esa tarea: se trata de Teodoro Muñoz Sedeño, a quien Velasco cataloga como «jefe de mi museo y clínica particular», personaje sobre el que más adelante volveremos ${ }^{22}$. Por cierto, que en el detallado texto que informa sobre los cursos se indica que éstos tendrán lugar no ya en Atocha 135 , sino en el nuevo domicilio (y sede del museo) del doctor: en el número 100 (hoy el 102) de esa misma calle madrileña. Esta nueva vivienda no se cita en los textos autobiográficos de Velasco ni en ninguna otra bibliografía. Sin embargo, el cambio de residencia y la nueva instalación de su museo se mencionan de forma expresa en otros dos sueltos de prensa: en La Correspondencia de España (20 de septiembre de 1862) y en El Genio quirúrgico (30 de septiembre de 1862). Lo extraño del caso es que justo un año más tarde, el 7 de octubre de 1863, el mismo periódico médico informa de la nueva apertura de los cursos y ahora dice que tendrán lugar en el domicilio y museo del doctor, "calle de Atocha, número 135». Quizás se trate en este último caso de un lapsus, pero no podemos confirmarlo. Es posible, por tanto, que al menos durante un año (antes del traslado a la nueva casa de Atocha 90) el domicilio-museo del doctor Velasco se situara en el número 100 de su muy amada calle de Atocha, nunca a más de cinco minutos a pie de la Facultad de Medicina.

\section{EL MUSEO DE ATOCHA 90 (1864-1874)}

Ya a comienzos de la década de 1860 el imparable incremento de las colecciones conduce a una situación agobiante en el domicilio de Atocha 135. Como su boyante situación económica se lo permite, Velasco soluciona el problema de forma radical: en 1863 adquiere un viejo edificio en la acera de enfrente, menos de treinta metros calle arriba, en el número 90 de Atocha (hoy el 92), lo derriba y allí levanta su nueva vivienda ${ }^{23}$ (véase figura 3 ). Desconocemos cuándo se produce el cambio efectivo de la residencia y el traslado del museo, pero sí sabemos que es en el nuevo domicilio donde fallece su hija María de la Concepción, y esto ocurre el 12 de mayo de 1864.

Es indudable que la muerte de Concha, de sólo 15 años, le resulta traumática; más aún porque se considera culpable del fatal desenlace. Ya anotamos que muy probablemente su inicial renuncia a la dirección del Museo Anatómico de la Facultad de Medicina está condicionada por tan dramático suceso. Es más,
Figura 3. Imagen actual del edificio construido por Velasco en Atocha 90 (hoy 92), que acogió su segundo museo

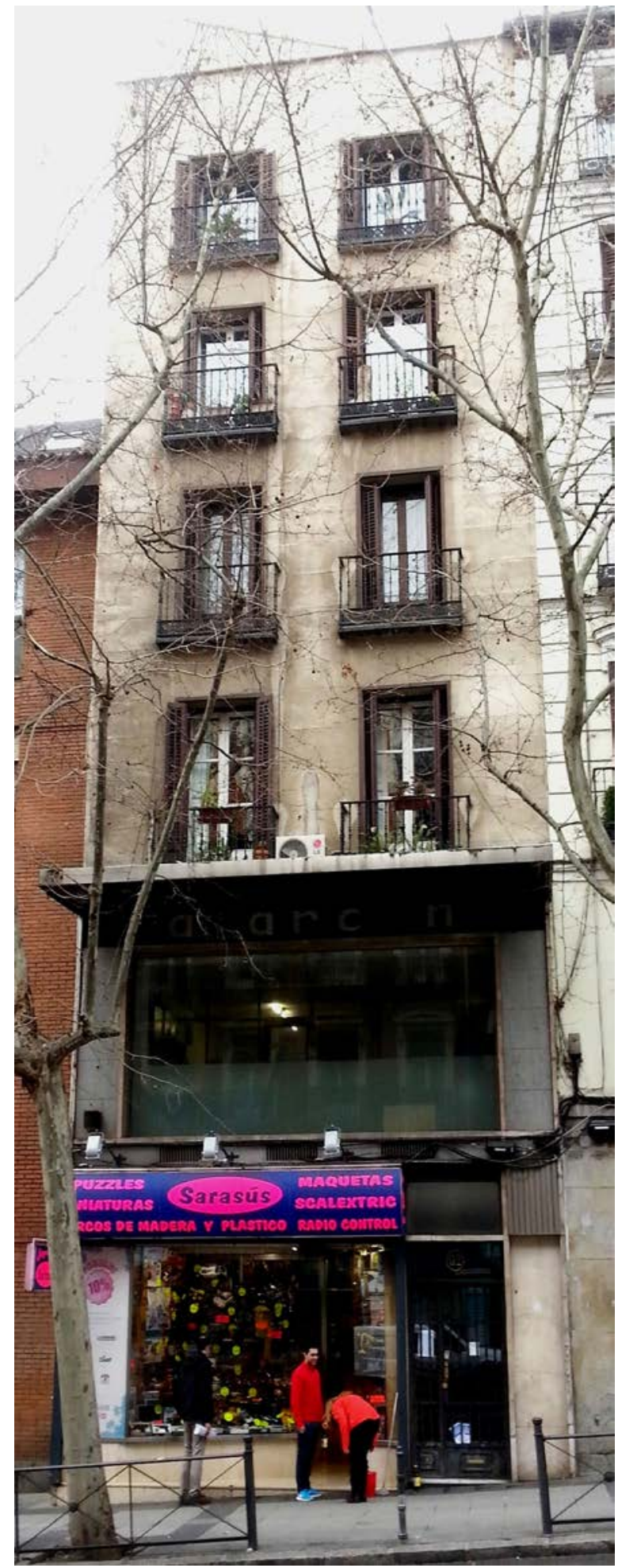


por la ausencia de noticias en la prensa (al menos no las hemos localizado), da la impresión de que durante varios meses el doctor se aísla del mundo, deja de ser el extraordinario personaje público que hasta entonces había sido. Pero el retiro no podía durar mucho. Antes de que los años revolucionarios lo instalen (de forma temporal) en lo más alto del escalafón universitario, Velasco retoma y da nuevo impulso a sus proyectos científico-profesionales. La ampliación y mejora de su museo se convierte en un objetivo prioritario, más aún que en etapas anteriores. A ello se suma el fomento de nuevas iniciativas con las que parece querer expandir su ámbito de intereses, dando paso a proyectos más ambiciosos, en los que la medicina y la anatomía se alían con las nuevas «ciencias antropológicas». La más importante es la creación de la Sociedad Antropológica Española (SAE) que, pese a sufrir notables altibajos (y alguna refundación) hasta su disolución en 1883 (tras la muerte del doctor), ocupa un destacado lugar en la historia de la antropología y la etnografía españolas ${ }^{24}$.

Aunque la inauguración oficial de la SAE tiene lugar el 5 de junio de 1865, el acto de constitución formal se celebra unos días antes, el 14 de mayo. Su anfitrión es el doctor Velasco y la reunión se organiza precisamente en el museo de Atocha 90. La reseña que hace un diario progresista de tan destacado acontecimiento nos permite conocer, aunque sea de forma sumaria, las características del nuevo centro ${ }^{25}$. La exposición ocupa el entresuelo de la finca y, según la actual ficha catastral, tendría una superficie útil de unos 152 metros cuadrados. El articulista lo explica con detalle:

El salón es muy capaz, recibiendo la luz por la parte superior, y sólido, gracias a varias columnas de hierro pintadas de blanco, con adornos dorados. A uno y otro lado se encuentran las paredes cubiertas por una elegante estantería, en la que campean ejemplares de anatomía patológica, monstruosidades, etc., ocultas por vidrieras con cortinillas.

En medio de la habitación, y dentro de una caja de cristal, hay un esqueleto. A la derecha y sobre atriles de terciopelo, están colocados colosales atlas de anatomía, y entre atril y atril magníficos y costosos microscopios que descansan sobre ménsulas, tapizadas también de terciopelo.

En el testero del salón y en la parte superior se lee: NOSCE TE IPSUM: A LAS CIENCIAS ANTROPOLÓGICAS: LIBRE EXAMEN.

Debajo, y a los lados sobre dos pedestales, se alzan los bustos del doctor González Velasco y su malograda niña.
A la derecha y sobre las columnas, en una línea dice: A los hombres ilustres de Tebas, Alejandría, Areópago de Atenas, Salerno, Montecasino, Guadalupe, Zaragoza, Valladolid y Madrid, y más adelante: $A$ las glorias de la patria.

La cornisa del testero de la derecha sostiene los bustos de Hipócrates, Aristóteles, Herófilo, Erasístrato, Galeno, [José Miguel] Guardia [Bagur (?)], [Juan] Drumen [Millet] y otros hombres notables en ciencias médicas.

Llama la atención la teatralidad del espacio: las columnas blancas con dorados, los atriles cubiertos de terciopelo, los bustos, las inscripciones y las cortinillas de algunos armarios, que impiden que personas sensibles o no preparadas contemplen aquello que nunca deberían contemplar. Aparece ya el famoso Nosce te ipsum, que años después campea sobre el friso de su gran Museo Antropológico, y también se hace mención a las «ciencias antropológicas», aunque en realidad los personajes y lugares históricos que se evocan en bustos y escritos pertenecen exclusivamente a la historia de la Medicina. La inscripción «Libre examen» reivindica la libertad de cátedra y sintetiza la ideología política progresista de nuestro protagonista.

Si al museo de Atocha 135 se habían acercado unos destacados ciudadanos marroquíes y el arzobispo de Toledo, el nuevo "Museo Anatómico-Patológico»" (véase figura 4) atrae a visitantes mucho más ilustres. En primer lugar, al príncipe heredero de Mónaco, el futuro Alberto I. Cuando Albert Honoré Charles Grimaldi se acerca al domicilio del doctor Velasco, en mayo de 1866, aún no ha cumplido los 18 años. ¿Qué hace en Madrid tan principesco personaje? Pues se encuentra en España porque se ha incorporado, o va a hacerlo de forma inmediata, a la Academia Naval, sirviendo luego en la Marina Española durante cuatro años, hasta alcanzar el rango de capitán de navío. Es bien conocida la pasión del príncipe por la navegación, la oceanografía y las exploraciones, pero también su interés por la prehistoria y la paleontología, que le lleva a fundar y sufragar algunas destacadas instituciones de investigación en Mónaco y Francia. La visita de 1866 prueba que esa atracción del futuro Alberto I por las ciencias antropológicas se remonta a su juventud. Desgraciadamente, lo único que sabemos de aquella jornada, un 3 de mayo, es que hizo de guía el oftalmólogo Francisco José Delgado Jugo, amigo de Velasco, y que el príncipe «observó con mucha atención todos los objetos de que se compone dicho museo, parándose muy particularmente en la sección de craneología» ${ }^{27}$. 
LUIS ÁNGEL SÁNCHEZ GÓMEZ

Figura 4. Carta manuscrita de Velasco con membrete del Museo Anatómico-Patológico de Atocha 90 (Biblioteca Nacional, mss. 12945/32)

Mss $12945 / 32$

IIISEO ANATÓMICO-PATOLOCGGCO

GABINETE DE CURACION

del

DR. PEDRO G. VELASCO

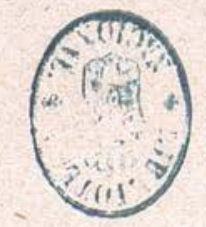
xisocmis, 90
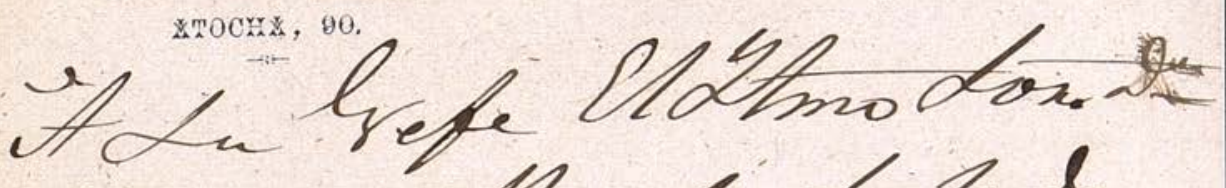

Cayetano Moset, Latuda Melicita y he Reilese ofreci-
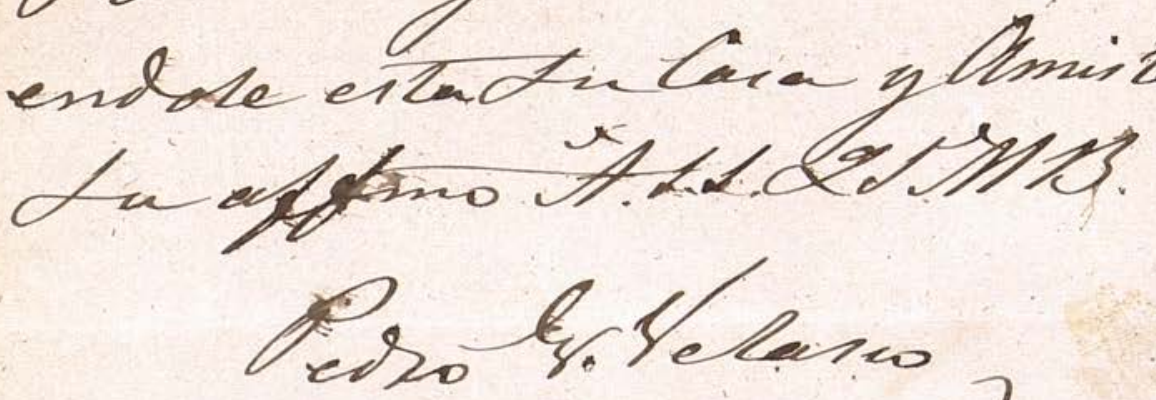

8

Asclepio, 67 (2), julio-diciembre 2015, p111. ISSN-L: 0210-4466. http://dx.doi.org/10.3989/asclepio.2015.29 
La egregia visita de 1866 es una buena propaganda para el doctor y su museo, pero Velasco es ambicioso y quiere más. Al año siguiente se le ofrece la oportunidad de mostrar a Europa, y al mundo, al menos una parte del rico entramado científico y museístico que ha levantado: la Exposición Universal de París de 1867. Participa con algunas piezas, e incluso es recompensado con una "mención honorífica» (González Velasco, 1869, p. 10), pero el asunto no va más allá. Mucho mejor se le presentan las cosas un año más tarde y en su propio país. El triunfo revolucionario de septiembre de 1868 y el destronamiento de Isabel II abren paso a un nuevo e intenso periodo en la historia de España; una época en la que muchos de los ideales políticos de Velasco se hacen realidad. También es un momento convulso, que afecta de forma intensa a la Universidad y a la propia Facultad de Medicina. En cualquier caso, la renovada coyuntura política beneficia de forma inmediata al doctor que, sin tener que superar oposición alguna (algo que él siempre había criticado), en diciembre de ese mismo año es nombrado catedrático de «anatomía quirúrgica, operaciones, apósitos y vendajes» ${ }^{28}$. Durante algo más de cinco años Velasco vive lo más parecido a un sueño hecho realidad: sigue en la cúspide de la cirugía práctica, dispone de un museo que no para de crecer y es, ipor fin!, catedrático de Anatomía en la Facultad de Medicina de la Universidad de Madrid. El sueño termina bruscamente unos meses después del golpe militar de Pavía: tras finalizar el curso en 1874, es cesado como catedrático ${ }^{29}$; no habrá ya ninguna otra vinculación oficial con la universidad.

Pero antes de que se produzca tan amarga derrota, Velasco sabe sacar partido del momento que vive. Como había ocurrido años atrás, pero ahora con mayor intensidad, el museo no es solo un recurso que prestigia a su propietario: también puede y debe ser utilizado en clave política e ideológica. En realidad, su mera existencia y el hecho de tratarse de un centro privado que supera con creces a los públicos equivalentes lo sitúa ya como referente simbólico de lo que se debería hacer y fomentar-pero ni se hace ni se fomenta- desde las administraciones públicas, ni siquiera durante el periodo revolucionario. Pero Velasco va aún más allá, utilizando de forma explícita su museo como herramienta política de propaganda a favor del progreso científico y social. Aunque es en el posterior museo del paseo de Atocha donde tienen lugar los acontecimientos políticos más relevantes de la vida del doctor, ya en el local que nos ocupa se documentan sendos llamativos encuentros entre ciencia y polí- tica: el primero esencialmente ideológico y personal; el segundo, de muchísimo mayor calado político y profesional, aunque al final no conduzca a (casi) nada.

Hablaremos en primer lugar de la visita que realiza, el 18 de mayo de 1871, un nutrido grupo de ciudadanos portugueses (entre ellos médicos, periodistas, profesores, ingenieros, militares y algún «rico propietario»), que forman parte de una extensa comitiva recibida unos días antes en la capital del Reino. Han llegado en tren, a través de la línea directa MadridLisboa que había sido inaugurada sólo cinco años atrás, en octubre de 1866, y lo han hecho gracias a la singular iniciativa de un destacado político español, progresista y ferviente defensor de postulados iberistas: Ángel Fernández de los Ríos. Aunque la estancia es de sólo una semana, la actividad que despliegan es muy intensa, e incluye una ofrenda en la tumba del gran héroe progresista e iberista asesinado solo unos meses antes en Madrid: el general Prim. Ese mismo día visitan el Museo Anatómico, acto que se recoge de forma entusiasta en La Iberia ${ }^{30}$ :

El señor Velasco enseñó a los visitantes la numerosa colección de cráneos que posee, ya normales, ya patológicos, así como el vaciado en yeso del famoso por lo cruel y despiadado conde de España ${ }^{31}$, y el natural del inmortal Vallés, llamado el divino ${ }^{32}$.

Entre los esqueletos hizo notar a los lusitanos el de un criminal que a los veintiocho años de edad había cometido catorce asesinatos [...], y el de un negro cuya desproporción en los radios de los miembros torácicos manifiesta la distancia que separa a la raza caucásica de la africana ${ }^{33}$.

Pieza por pieza y objeto por objeto, el señor Velasco hizo notar a sus huéspedes las inmensas riquezas científicas que posee [...].

El recorrido continúa con la contemplación de las piezas de anatomía patológica, los «poderosos microscopios» y el "arsenal de instrumentos quirúrgicos»; finalmente, los invitados conocen la cátedra (aula) y el laboratorio, "donde reputados artistas, bajo la dirección del señor Velasco, construyen en cera, cartón-piedra o escayola los ejemplares que enriquecen el museo».

Sólo unos días después de tan exitosa y significativa jornada, el 1 de junio, visita el museo de Atocha 90 el personaje más relevante que podría haberlo hecho nunca: nada menos que el rey Amadeo I. Curiosamente, sólo en dos medios se informa del acontecimiento: en un brevísimo suelto de El Imparcial y 
en un detallado y entusiasta artículo de La Iberia, el diario republicano e iberista que dirige precisamente Fernández de los Ríos. La prensa conservadora, y otra que en teoría no lo es tanto, no parece interesada en destacar tan notable éxito personal de Velasco. Pese al boicot informativo, el acontecimiento debe ser interpretado como un rotundo respaldo del nuevo y constitucional monarca al empeño científico de nuestro protagonista. Así lo hace La Iberia, donde se afirma que «El Rey, al honrar la casa de nuestro amigo, hombre del pueblo, y cuyo amor a la humanidad y a la ciencia raya en lo imposible, ha dado una prueba más de la ilustración que le distingue y de lo digno que es de ocupar el solio español $»^{34}$.

Como el museo de Atocha 90 no deja de recibir nuevos materiales, a finales de 1872 se puede dar por colapsado. El éxito de las dos visitas reseñadas, el renovado ambiente político que vive el país y el extraordinario reconocimiento social de que disfruta hacen que el siempre enérgico Velasco proyecte planes de futuro para su museo que permitan resolver de forma drástica, y por mucho tiempo, los problemas de espacio. Su objetivo es extremadamente ambicioso: ya no se plantea comprar o hacerse construir una casa más grande en la que instalar su nuevo museo; ahora pretende levantar un palacio-museo e instalar en él su propia casa. Aunque disfruta de una desahogada posición económica, la inversión económica que requiere el proyecto parece quedar fuera de sus posibilidades. En esta coyuntura, la combinación de ingenuidad y grandilocuencia de que hace gala Velasco en no pocas ocasiones le llevan al extremo de proponer al rey Amadeo I algo muy poco sensato: «construir en esta corte un museo anatómico humano comparado y de historia natural, que será de su propiedad, y cuyo coste de un millón de reales será sufragado por el Estado, comprometiéndose el mismo Sr. Velasco a pagar al Estado 4.000 duros anuales» ${ }^{35}$. Como era de esperar, el apoyo moral recibido por parte del rey en junio del año anterior no sirve de nada: el Ministerio de Fomento rechaza la solicitud. Al igual que en otras ocasiones, el contundente traspié no arredra al doctor, más bien produce el efecto contrario: si el Estado no financia su museo, tendrá que asumir personalmente los gastos de su construcción. Y no lo duda: a primeros de marzo de 1873 comienzan las obras de explanación de su nuevo y "grandioso museo» al final del entonces paseo de Atocha; el 16 de abril (onomástica de su esposa) se coloca la primera piedra.

Ese mismo año echa a andar otro proyecto largamente anhelado por Velasco: la edición de su propia revista de estudios médicos y anatómicos, El Anfiteatro Anatómico Españoß ${ }^{36}$ (véase figura 5). Al margen de cualquier otra consideración sobre sus contenidos, lo que nos interesa es que gracias a esta publicación disponemos de más y mejor información sobre las actividades desarrolladas en los dos últimos museos de Velasco, con datos precisos sobre la incorporación de nuevos materiales.

Como en épocas previas, las piezas que se incorporan al museo de Atocha 90 durante estos años siguen teniendo su origen en actos médicos protagonizados o conocidos por Velasco. El doctor mantiene vivo su interés por coleccionar modelos, preparaciones y ejemplares reales de llamativas patologías y de casos teratológicos. Puede tratarse de un enorme «tumor canceroso», de algún adenoma gigantesco (véase figura 6), del vaciado de la cabeza de «un idiota toledano», de un alargadísimo cráneo dolicocéfalo (con presuntos indicios de que «el individuo se masturbaba») o de fetos humanos monstruosos (véase figura 7), alguno de los cuales se consigue tras «sacrificar algún dinero y trabajar mucho hasta persuadir a un sepulturero de la utilidad científica que resultaba en examinar dicho caso ${ }^{37}$.

En numerosas ocasiones el interés de las piezas que ingresan se circunscribe al ámbito de la casuística teratológica, lacra de la que Velasco es sólo una víctima más durante aquellos años. También se menciona en El Anfiteatro la entrada de objetos no vinculados con la práctica médica, unos adquiridos por el doctor y otros procedentes de donaciones. Como en el caso de la tzantza que mencionábamos en otro lugar, algunos materiales combinan un presunto interés anatómico-antropológico con el etnográfico. Así pudo ocurrir con un pretendido "cráneo australiano de una cabeza momificada». Sin embargo, será a partir de 1875 , ya en el nuevo museo, cuando la donación de "curiosidades» de todo tipo y condición se incremente de manera exponencial.

A pesar de lo que acabamos de anotar, quizás el regalo más singular hecho nunca al doctor Velasco sea el que se documenta en un suelto de prensa en marzo de 1873: «Se ha autorizado a D. Manuel Taín para trasladar al museo anatómico patológico del doctor González de Velasco el cadáver momificado de la hija de aquél, que falleció ha seis años a los 13 de edad ${ }^{38}$. El apellido correcto de tan peculiar individuo es Tarín, y la fallecida, su hija Carmen. Y bien, ¿qué interés tiene tan escabroso asunto? Pues un interés grande, aunque relacionado exclusivamente con la leyenda del doctor Velasco y su hija difunta: como ha demostrado hace 
Figura 5. Cabecera de El Anfiteatro Anatómico Español (enero de 1873)

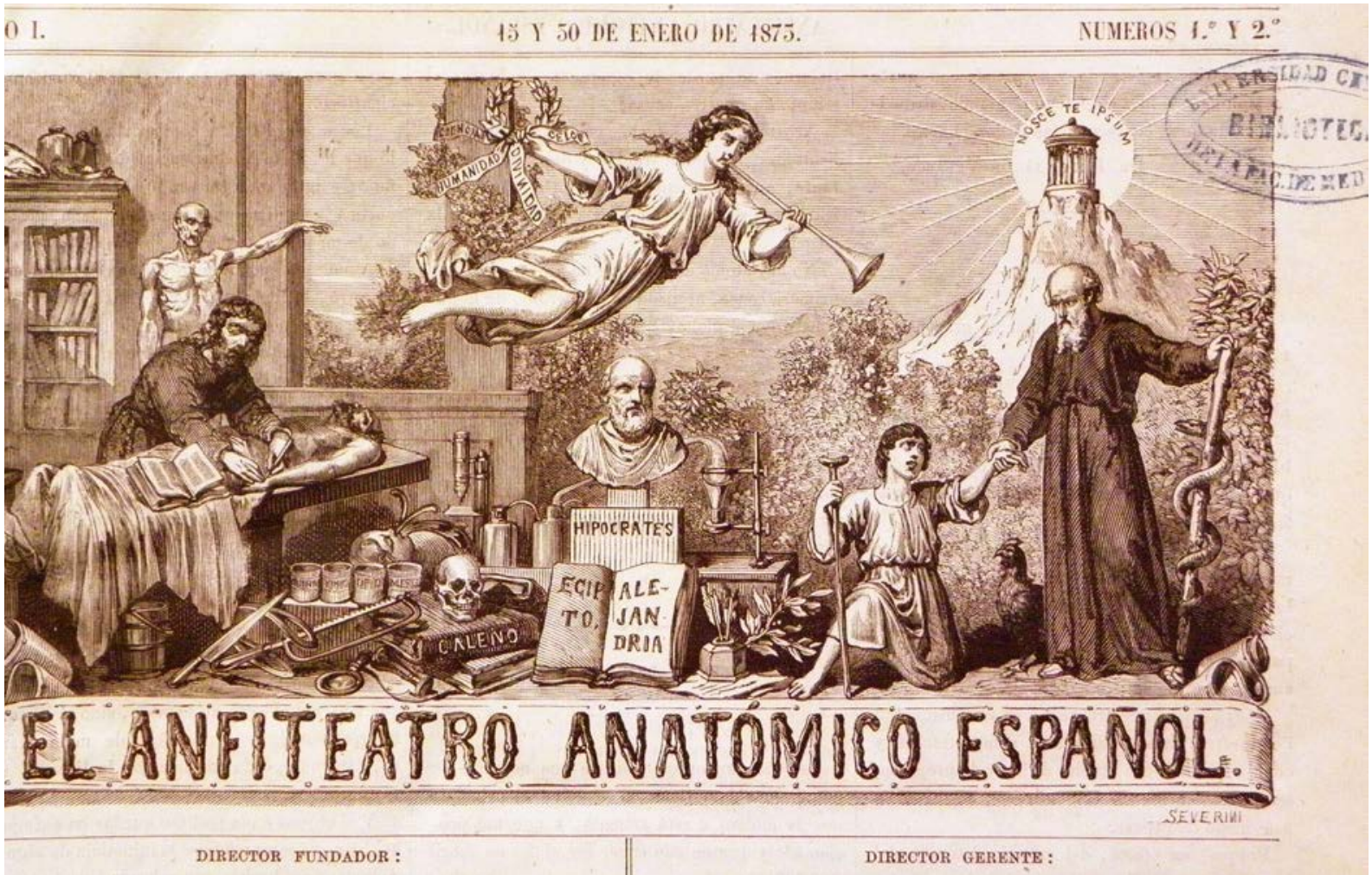

Figura 6. Modelo de busto con "adenomas con degeneración cancerosa", perteneciente al Museo Anatómico-Patológico de Atocha 90 (El Anfiteatro Anatómico Español, no 4, 15 de marzo de 1873, p. 48)

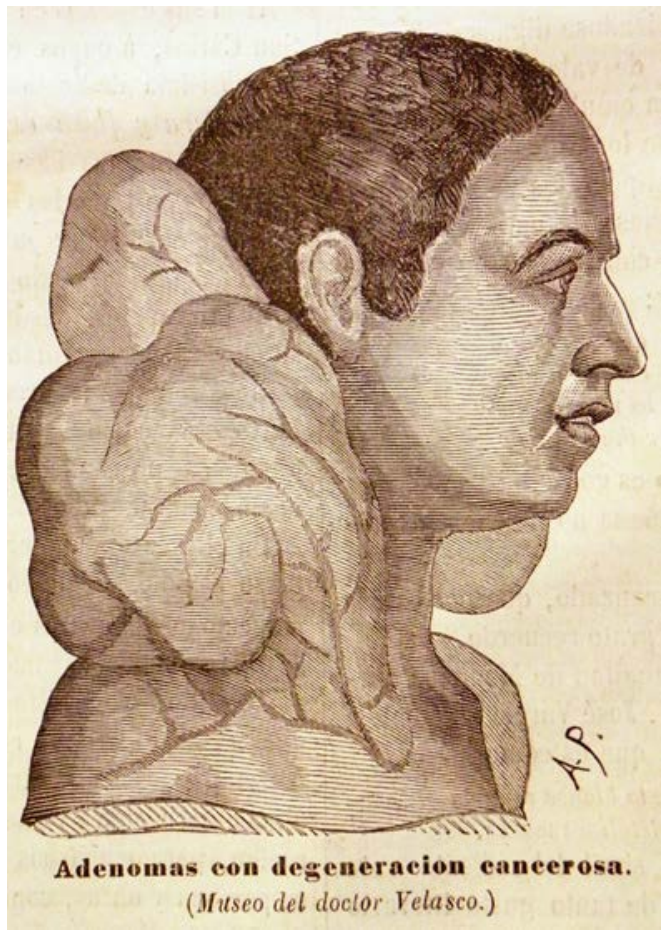

Figura 7. "Feto monstruoso", conservado en el museo de Atocha 90 (El Anfiteatro Anatómico Español, no 22, 15 de diciembre de 1873 , p. 262)

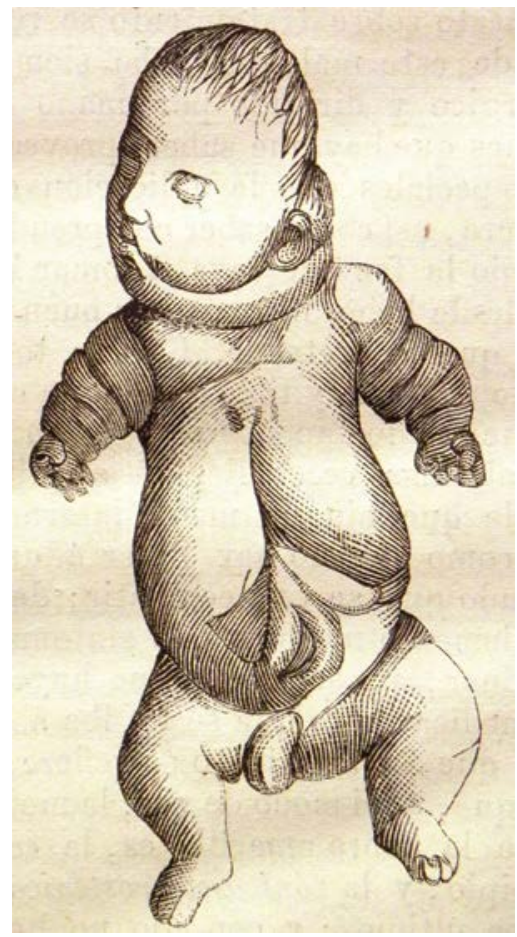


poco una detallada y completa investigación (Dorado et al., 2010), la momia en cuestión es la que durante décadas se ha conservado (y se conserva) en la Facultad de Medicina de la Universidad Complutense con una cartela (errónea) que dice «534 Momia de la hija del Dr. Velasco» (véase figura 8), y se correspondería con aquella que según la leyenda era visitada todas las noches por su presunto novio, el ya citado Teodoro Muñoz Sedeño, ayudante del propio doctor ${ }^{39}$.

Figura 8. Presunta momia de la hija del doctor Velasco, conservada inicialmente en el museo de Atocha 90 y luego trasladada a la Facultad de Medicina de Madrid. En realidad, se trata de la momia de la hija del médico Manuel Tarín, donada a Velasco en 1873 (Crónica, 7 de julio de 1935)

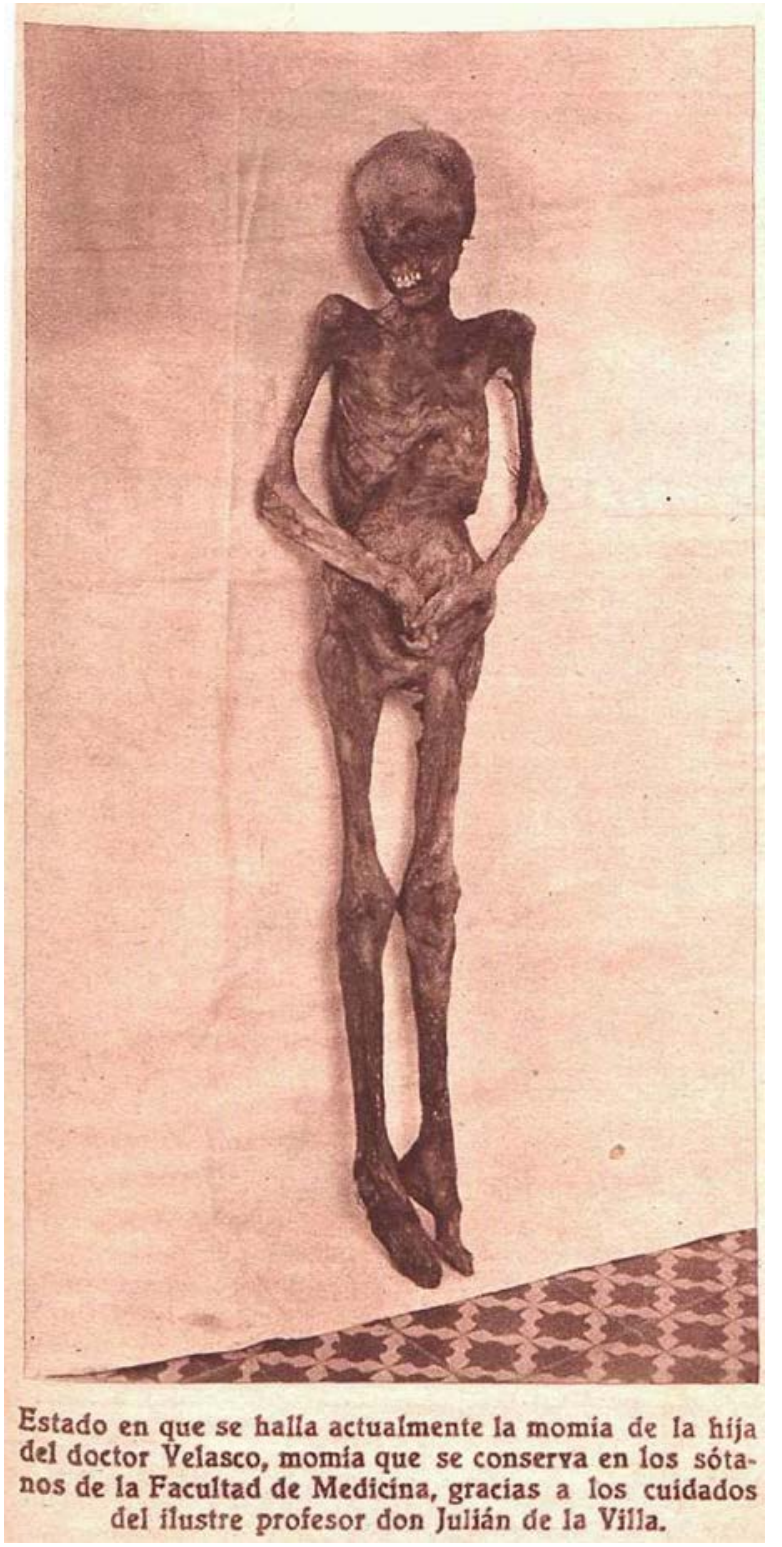

Durante 1873 las obras del nuevo museo avanzan, aunque no sin contratiempos, por lo que el propósito de inaugurarlo en la primavera de 1874 resulta una quimera. Como contrapartida, la actividad que se despliega durante todo ese año en la sede de Atocha 90 es ciertamente intensa, sobre todo tras la refundación de la Sociedad Antropológica Española, pues allí siguen teniendo lugar, hasta la inauguración del nuevo edificio, sus reuniones y conferencias, algunas de las cuales se publican luego en el órgano de expresión de la Sociedad, la Revista de Antropología, cuyo primero número sale a la luz a finales de enero de 1874. En octubre de este año Velasco traslada ya su famosa y concurrida "visita de pobres» al nuevo edificio. Unos meses después, probablemente entre enero y marzo de 1875, las colecciones de Atocha 90 se instalan en los salones del impresionante Museo Antropológico.

Gracias a una interesantísima litografía que se publica en El Anfiteatro ${ }^{40}$, a modo de homenaje de despedida al que se califica como "primitivo museo», podemos conocer hasta dónde había llegado el segundo proyecto museográfico doméstico de Velasco (véase figura 9).

Casi todo lo que se describe en el artículo de La Soberanía Nacional, de 15 de mayo de 1865, se puede contemplar en esta imagen de 1874: el gran lucernario $^{41}$, las columnas de hierro forjado, el esqueleto en la vitrina, las dos filas de armarios, los atriles que guardan los atlas de anatomía, los bustos de personajes de la Antigüedad, los del doctor y su hija (al fondo de la sala) y las inscripciones de los muros, aunque de éstas últimas sólo se distingue la que se sitúa sobre la mesa que parece ocupar el doctor Velasco, que dice «A LAS CIENCIAS ANTROPOLÓGICAS». No se ven los microscopios, que debían de guardarse en otra dependencia, pero sí aparecen otros muchos elementos que no se citan en el artículo y que, al menos en parte, se incorporan al museo en fechas posteriores. Llaman la atención los animales disecados y el maniquí con lanza, sombrero y abalorios, que habrá de ocupar un destacado lugar en el salón grande del nuevo museo. En un plano posterior se sitúa una llamativa momia vendada, seguramente la que ya está presente en el domicilio de Atocha 135 y que había preparado (¿cómo imitación de las egipcias?) el propio Velasco. Detrás se observa un maniquí anatómico a tamaño natural, con el brazo izquierdo levantado, que también se exhibe poco después en el gran Museo Antropológico. Los armarios se muestran repletos de piezas anatómicas y teratológicas, aunque en una de las vitrinas (la que hace pendant a la del esqueleto) parecen guardarse también aves y reptiles. Entre estas dos vitrinas se puede ver (sobre 
Figura 9. El Museo Anatómico-Patológico de Atocha 90 (El Anfiteatro Anatómico Español, no 36, 15 de julio de 1874 , p. 150)

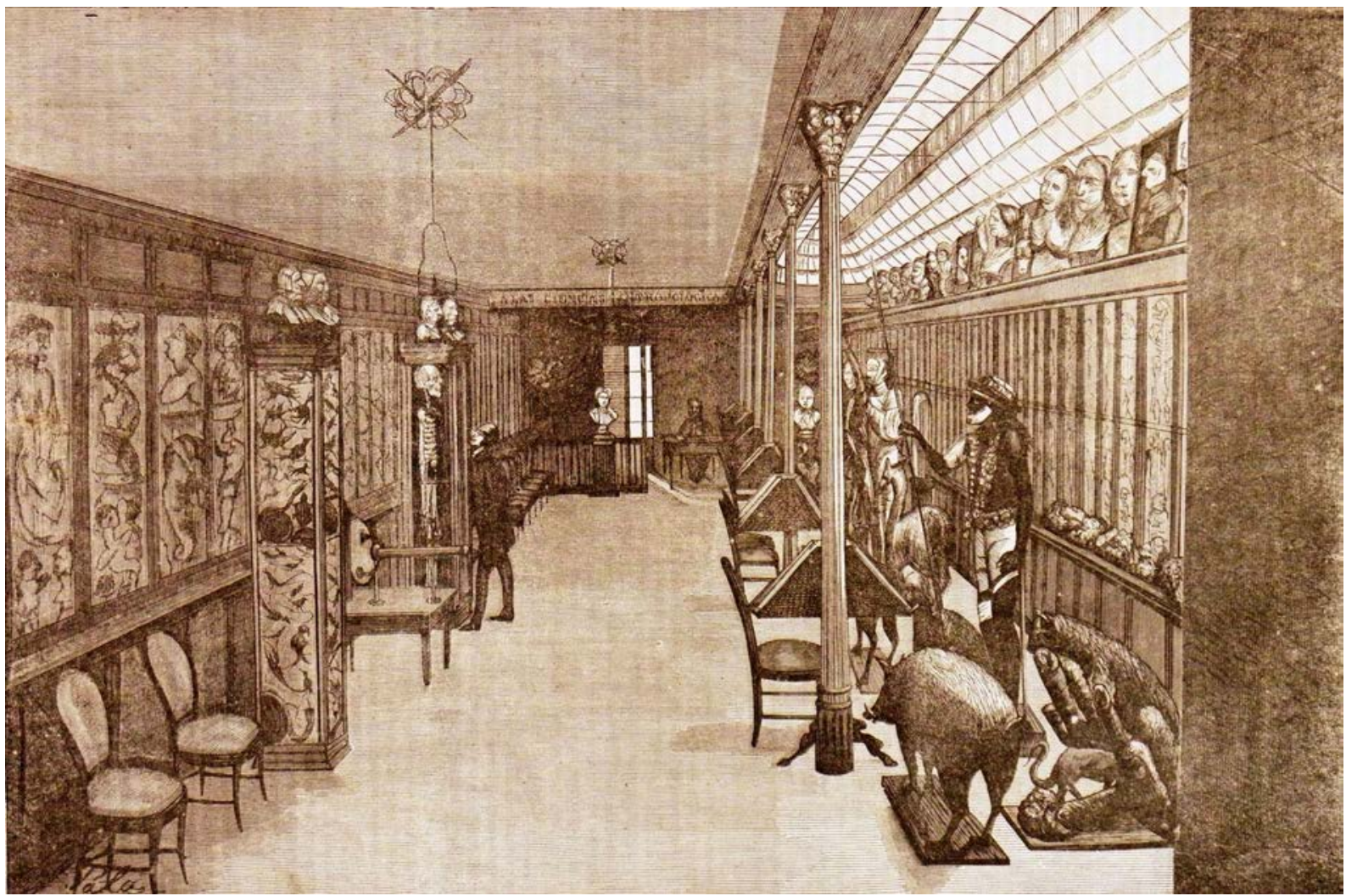

una mesa baja) una máquina eléctrica de Ramdsen, utilizada habitualmente para hacer demostraciones del fenómeno de la electricidad y entonces sin ninguna aplicación práctica en el ámbito médico, un ejemplo más del extenso abanico de intereses del doctor ${ }^{42}$.

La sugerente litografía que comentamos demuestra que el salón de Atocha 90 no da para más. La creación de un nuevo museo responde pues a una necesidad objetiva de espacio; cuestión diferente es que la empresa se considerase razonable por cualquier otro mortal que no fuera Velasco. Fuera sensato o no, el tozudo segoviano al final lo consigue: el 29 de abril de 1875 el joven rey Alfonso XII inaugura el nuevo y grandioso Museo Antropológico, el templo-museo que un médico heterodoxo y republicano consagra a una hija fallecida (y momificada) y a un país moribundo (y anquilosado) ${ }^{43}$.

\section{CONCLUSIONES}

Tras la sumaria revisión que hemos realizado, ¿qué conclusiones podemos extraer sobre el significado y la relevancia de estos dos museos anatómicos domésticos? En primer lugar, es obvio que sin su formación, sin el empeño puesto por Velasco en disponer de colecciones médico-anatómicas en su propio domicilio, el futuro proyecto del Museo Antropológico no hubiera podido materializarse. También es evidente que, en comparación con este último, las dimensiones de aquellos son muy modestas, lo cual no es obstáculo para asumir que debieron de cumplir sobradamente el doble objetivo para el que habían sido diseñados: mejorar y prestigiar la docencia médica privada impartida por su propietario y prestigiar al propio doctor como profesional de la cirugía, al mostrarse capaz de trascender (en clave científica y académica) la mera proyección empírica de sus habilidades con el bisturí.

Aunque sería necesario analizar la cuestión con mayor detalle, lo que sabemos de ambos museos nos permite afirmar que su orientación y contenidos no difieren de lo que se documenta en centros similares europeos ${ }^{44}$. Nos referimos a colecciones formadas por médicos, con fines científico-docentes, instaladas mayoritariamente en sus domicilios. Su base es médico-anatómica, pero es habitual que incluyan parcelas dedicadas a la antropología (física), la etnografía, la zoología y hasta la mineralogía, sin 
dejar de acoger siempre muy variadas «curiosidades». También hemos de anotar que los materiales de todos estos centros no son muy diferentes de los que exhiben los «museos anatómico-antropológicos» comerciales, tanto estables como itinerantes, habituales en Europa a partir de la década de 1840. No obstante, es evidente que los comerciales optan por escenificaciones más llamativas y espectaculares y que su objetivo esencial no es la docencia, sino la obtención de beneficios económicos; aunque precisamente el factor educativo está siempre presente en sus reclamos propagandísticos.

Para terminar, debemos llamar la atención sobre una circunstancia especialmente significativa: el doctor Velasco es de uno de los poquísimos propietarios de colecciones anatómicas académicas que consigue reconvertirlas en un verdadero museo; y bien po-

\section{NOTAS}

* Estudio realizado en el ámbito del proyecto de investigación "Ciencia y espectáculo de la naturaleza. Viajes científicos y museos de historia natural», codirigido por M. A. Puig-Samper y Carmen Ortiz (ref. HAR2013-48065-C2-2-P).

1 Temprana en el contexto de su nuevo proyecto de vida en Madrid, donde llega sin recursos en 1838 y se gana la vida durante unos años como criado, después de haber sido porquero, fraile y soldado. Junto con sus escritos autobiográficos, la principal fuente para conocer la vida y la obra de Velasco es el texto que publica su discípulo Ángel Pulido en 1894, pero ni en ese trabajo ni en la bibliografía posterior se dice nada sobre los museos que estudiamos. Sí se hace alguna breve anotación en un artículo sobre historia de la medicina de Porras Gallo (2002) y en el extenso estudio sobre Velasco publicado por Giménez Roldán (2012). Además de los textos citados, ofrecen datos biográficos sobre Velasco -casi todos poco o nada originales- Muguerza (1935-36), Benavente (1962 [1944]), Moreno (1945), Perera (1967), Cabezas (1971) y Uranga (1973). A estos habría que añadir trabajos de índole más estrictamente académica (interesados por la historia de la medicina o la antropología) que hacen referencia a su obra: Verde Casanova (1980), Arquiola (1986), Puig-Samper (1982), Puig-Samper y Galera (1983), Ronzón (1991), Romero de Tejada (1992), varios artículos en Ortiz y Sánchez (1994), Martin-Márquez (2003), Goode (2009), Dorado et al. (2010) y Valis (2011).

2 En París queda impresionado por el Museo Dupuytren, que será la institución a la que siempre trate de emular e incluso superar. En realidad, este museo es obra del gran médico e investigador menorquín Mateo Orfila (1787-1853), algo que destaca con orgullo patriótico el propio Velasco.

3 Este museo (articulado en varias secciones, de ahí el uso del plural) es heredero del Gabinete Anatómico del Real Colegio dría ser el único que, en la Europa del siglo XIX, es capaz de alojar su creación en un nuevo y suntuoso edificio concebido expresamente con ese objetivo. Otros muchos acaban donándolas o transfiriéndolas a instituciones públicas, que (si lo consideran oportuno) son las encargadas de instalarlas en la debida forma. Desgraciadamente, muchos de estos museos son pronto desmantelados, ya desde finales del XIX: se consideran obsoletos para la docencia y tampoco se valoran desde una perspectiva patrimonial, y ello a pesar de la relevancia histórico-cultural de muchas de sus colecciones. Éste es también el destino que sufre el gran Museo Antropológico de Velasco, que pese a sus singularidades y limitaciones fue y continúa siendo (ya solo en el recuerdo) el más relevante museo médico-anatómico-antropológico construido nunca en España.

de Cirugía de San Carlos, que ordena crear Carlos III en 1787, y antecesor del actual Museo de Anatomía "Javier Puerta» de la Facultad de Medicina de la Universidad Complutense, que trata de mantener vivo su entusiasta director, el profesor Fermín Viejo. Más que un museo, se trata de una extraordinaria colección anatómica que requeriría de mucha mayor atención (e inversión económica) por parte de las instituciones públicas.

4 Velasco reedita esta memoria en 1868, con el único añadido de un «proyecto de decreto de reorganización de los trabajos y museos de Anatomía de las Facultades de medicina y cirugía de España».

5 Su hija Concha muere el 12 de mayo de ese mismo año. Es muy posible que la renuncia a la dirección del centro esté condicionado por tan dramático acontecimiento. No obstante, hemos comprobado que retira esta primera dimisión, renunciando definitivamente en 1868.

6 Pudo haber estado a la altura del actual número 107, pero parece que el edificio que hoy se contempla es posterior, construido hacia 1880.

7 Es más, en su folleto autobiográfico González Velasco (1864, p. 25) asegura que todos los museos anatómicos deben estar "cerrados siempre para las señoras y los profanos», aunque éste es un principio que en realidad no cumple.

8 El Genio quirúrgico, 7 de octubre de 1862, p. 590. El acceso a la prensa histórica ha sido posible gracias a la magnífica Hemeroteca Digital de la Biblioteca Nacional (http://hemerotecadigital.bne.es).

9 La sociedad española no está acostumbrada a este tipo de centros. A diferencia de lo que ocurre en otros países, en 
España los museos anatómicos no son frecuentes, menos aún los particulares. La prensa de Madrid y Barcelona (y en mucha menor medida la de otras capitales) recoge en la década de 1860 la presentación de algunos «museos anatómicos» comerciales itinerantes. También se menciona algún pequeño "museo» particular no estrictamente comercial, pero sin apenas proyección pública. Los hay también en casi todas las Facultades de Medicina y en algunos hospitales, tanto civiles como militares, pero la mayoría son de escasa relevancia y acceso restringido. No obstante, en la década de 1880 (y luego durante el primer cuarto del siglo XX) los museos anatómicos comerciales viven un nuevo periodo de apogeo, muy especialmente en Barcelona (March, 2014).

10 La Correspondencia de España (Madrid), 18 de septiembre de 1860. Probablemente la estancia de estos personajes en Madrid está relacionada con la firma del Tratado de Wad-Ras, en abril de ese mismo año, entre España y el Sultanato de Marruecos, y la visita del sultán Muley el-Abbas al año siguiente.

11 Sin duda se trata de la momia que aparece en la litografía publicada en El Anfiteatro Anatómico Español (que más adelante comentamos) en 1874 , en la que se representa el museo de Atocha 90.

12 La España (Madrid), 28 de mayo de 1863. La visita es desconcertante en un contexto católico y sobre todo español. En el mundo protestante, y especialmente en Inglaterra y Estados Unidos, los miembros de la jerarquía eclesiástica suelen tener acceso privilegiado a este tipo de centros durante el siglo XIX (Bates, 2008; Wolf, 2010).

13 De hecho, en la misma página del diario que informa de esta visita, otro de los sueltos indica que el propio cardenal acaba de prohibir dos novelas por ser «abiertamente contrarias a la fe y las buenas costumbres». Se trata de Los miserables, de Víctor Hugo, y de La judía errante, del catalán Ceferino Tresserra.

14 Ejemplar de 7 de enero de 1862.

15 Inflamación patológica, de gran tamaño, de alguna parte del cuerpo.

16 Tuberculosis o inflamación ósea que afecta a los huesos largos de pies y manos.

17 Quistes por acumulación de líquido, esencialmente en los testículos.

18 El Genio quirúrgico, 15 de octubre de 1862.

19 La Iberia, 31 de abril de 1860.

20 Escenas contemporáneas, n - 4, 25 de septiembre de 1862, p. 96.

21 El Genio quirúrgico, 7 de octubre de 1861.

22 El Genio quirúrgico, 7 de octubre de 1862.
23 El expediente de construcción se conserva en el Archivo de Villa, en Madrid, con la signatura 4-280-22. El edificio continúa en pie, sin placa alguna que recuerde que allí vivió y tuvo su museo el doctor Velasco.

24 Sobre la SAE, sus actividades y publicaciones, véase Verde (1980), Galera, Puig-Samper y Pelayo (1984), Ronzón (1991: 258-289), Puig-Samper (1994) y Ayarzagüena (1997).

25 La Soberanía Nacional, 15 de mayo de 1865.

26 Esta es la denominación que aparece en el membrete de una carta, sin fechar, que se guarda en la Biblioteca Nacional (mss. 12945/32) y que es uno de los escasísimos documentos originales de Velasco que se conserva. Véase figura 4.

27 La Correspondencia de España, 5 de mayo de 1866.

28 La Correspondencia de España, 29 de diciembre de 1868.

29 La Correspondencia de España, 9 de febrero de 1874

30 La Iberia, 20 de mayo de 1871.

31 Sin duda se trata de Roger-Bernard-Charles d'Espagnac de Ramefort (1775-1839), conocido como Conde de España y Carlos de España, noble y militar francés enrolado en el Ejército Español y fiel servidor de Fernando VII. Su sadismo y crueldad fueron proverbiales, muy especialmente durante su etapa como capitán general de Cataluña. Asesinado con saña por sus propios correligionarios, se cuenta que alguien se apoderó de su cráneo. En La senda dolorosa (1928), Pío Baroja se hace eco de la leyenda, presentando al frenólogo catalán Mariano Cubí en una mágica y alucinada conversación con la calavera del conde.

32 Francisco Vallés (o Valles), conocido como «El divino» (15241592), es una de las figuras de la historia de la medicina idolatradas por Velasco. Cuando construye su gran museo del paseo de Atocha, una escultura suya (acompañada por la de Miguel Servet) flanquea la gran escalinata de acceso. Curiosamente, los restos de Vallés fueron localizados no hace mucho, en abril de 2011, en la Capilla de San Ildefonso de la Universidad de Alcalá de Henares. Habían sido exhumados en 1862 y trasladados a una urna que hasta aquella fecha se daba por desaparecida. Según EI Siglo Médico (28 de diciembre de 1862), Velasco participó en el acto de reinhumación y obtuvo autorización para modelar el cráneo y un fémur de Vallés. No es posible, por tanto, que en 1871 mostrara a los visitantes portugueses el cráneo «natural» del médico, sino la citada reproducción.

33 La ideología "progresista» de Velasco, del diario y de los visitantes no es incompatible con tan singular y racista anotación.

34 La Iberia, 2 de junio de 1871.

35 El Imparcial, 9 de noviembre de 1872.

36 De periodicidad quincenal, se publica con esta cabecera hasta diciembre de 1875; a partir de enero de 1876 aparece 
como El Anfiteatro Anatómico Español y El Pabellón Médico, pues absorbe a este último. Desde enero de 1881 se refunde con la Revista de Medicina y Cirugía Prácticas, y deja de ser propiedad del doctor Velasco. Una dato curioso: en el grabado alegórico que adorna la portada de la revista, la figura de Fama porta una corona con cintas en las que se leen los términos "Ciencia», "Celo», "Humanidad» y "Divinidad». Son las cuatro cualidades que debe poseer todo profesional de la medicina, aunque obviamente en la última se ha deslizado un grave error, pues debería decir «Dignidad». La aclaración se hace en el número de 15 de febrero de 1873, pero el grabado nunca se corrige.

37 El Anfiteatro, número 22, 15 de diciembre de 1873, p. 262. Esta publicación no está disponible en la Hemeroteca Digital de la Biblioteca Nacional. Se ha consultado en la biblioteca de la Facultad de Medicina de la Universidad Complutense.

38 El Imparcial, 28 de marzo de 1873.

39 La leyenda cuenta que tras la compra del Museo Antropológico por el Estado en 1887, la momia de Concha es trasladada a la Facultad de Medicina, y que allí la visita todas las noches -lloroso y alcoholizado- quien fuera su novio, el doctor Muñoz Sedeño. Lo que en realidad ocurre es que,

\section{BIBLIOGRAFÍA}

Alberti, Samuel J. M. M. and Hallam, Elisabeth (eds.) (2013), Medical Museums. Past, Present, Future. Londres, The Royal College of Surgeons of England.

Arquiola, Elvira (1986), "González Velasco, reformador de los saberes morfológicos", Medicina \& Historia. Revista de Estudios Históricos de las Ciencias Médicas, 14, pp. 3-26.

Ayarzagüena Sanz, Mariano (1997), "La Sociedad Antropológica Española (SAE) y el nacimiento de la ciencia prehistórica en España". En: La cristalización del pasado: Génesis y desarrollo del marco institucional de la arqueología en España, Málaga, Universidad de Málaga, pp. 295-301.

Bates, A. W. (2008), “'Indecent and Demoralising Representations': Public Anatomy Museums in mid-Victorian England", Medical History, 52 (1), pp. 1-22, [en línea], disponible en http://www.pubmedcentral.nih.gov/articlerender. fcgi?artid=2175054, [consultado el 7 de mayo de 2014].

Benavente, Jacinto (1962) [1944], Recuerdos y olvidos (Memorias), Madrid, Aguilar.

Cabezas, Juan Antonio (1971), "El doctor Velasco, personaje real de un cuento de Poe. La verdadera biografía y la leyenda necrofílica de un catedrático de anatomía de San Carlos", $A B C, 28$ de agosto, pp. 32-37.

Dorado Fernández, Enrique et al. (2010), "La momia de la hija del doctor Velasco. Disección de una leyenda", Revista de la Escuela de Medicina Legal, 13, pp. 10-30, [en línea], dis- contraviniendo los deseos de su difunto esposo, la viuda de Velasco devuelve el cuerpo de su hija a la Sacramental de San Isidro, en Madrid, en 1886 (Dorado et al. 2010, p. 21).

40 Número 36, 15 de julio de 1874, p. 150.

41 Según información proporcionada por Antonio Gómez Iruela (profesor de la Escuela de Arte número 10 de la Comunidad de Madrid y conocedor del inmueble), hace años que el lucernario fue sustituido por una «plataforma de hormigón que hoy es el patio del edificio a la altura del segundo piso».

42 Agradezco a Ignacio de la Lastra González (del Museo Nacional de Ciencia y Tecnología, en su sede de Madrid) la identificación e información proporcionada sobre este aparato.

43 En Sánchez Gómez (2014) se estudia con algún detalle este importante museo, demostrándose que fue mucho más que un simple depósito de fetos monstruosos y curiosidades, como algunos han pretendido.

44 En la reciente obra colectiva editada por Alberti y Hallam (2013) se puede acceder a interesante información sobre las características de los principales museos médicos y anatómicos creados en Europa y Estados Unidos desde finales del siglo XVIII.

ponible en: http://revistas.ucm.es/index.php/REML/article/ view/REML1010130010A/22910, [consultado el 5 de noviembre de 2013].

Giménez Roldán, Santiago (2012), El Doctor Velasco. Leyenda y realidad en el Madrid decimonónico. Madrid, Editorial Creación.

Goode, Joshua (2009), Impurity of Blood. Defining Race in Spain, 1870-1930. Baton Rouge, Louisiana State University Press.

González Velasco, Pedro (1854), Museo de Dupuytren, de París, erigido a expensas del Estado por los desvelos de D. Mateo Orfila [...] con una reseña de los gabinetes de París y Londres. Madrid, Imprenta de Don Alejandro Gómez Fuentenebro.

González Velasco, Pedro (1864), Reseña histórica de los trabajos anatómicos del doctor don-, escrita por el mismo en sus últimos viajes al extranjero. Dedicada al profesorado español. Madrid, Imprenta de Manuel de Rojas.

González Velasco, Pedro (1868), Reseña histórica de los trabajos anatómicos del doctor don-, escrita por el mismo en sus últimos viajes al extranjero. Dedicada al profesorado español. Madrid, Imprenta Médica de M. Álvarez

March, Enric H. (2014), "El control del espacio urbano y del cuerpo humano: los espectáculos anatómicos", XIII Coloquio Internacional de Geocrítica. El control del espacio y los espacios de control. Barcelona, 5-10 de mayo de 2014. Universitat de Barcelona, [en línea], disponible en http://www. 
ub.edu/geocrit/coloquio2014/Enric\%20H\%20March.pdf, [consultado el 29 de julio de 2014].

Martin-Márquez, Susan (2003), "Anatomy of a Black Legend: Bodies of Cultural Discourse and Madrid's National Museum of Anthropology", Journal of Spanish Cultural Studies, 4 (2), pp. 205-222.

Moreno, Luciano (1945), "El Dr. González de Velasco y la fundación del Museo Antropológico", Trabajos del Instituto Bernardino de Sahagún de Antropología y Etnología. Antropología, I, pp. 9-22.

Muguerza Bernal, Tomás (1935-36), "Breve reseña biográfica del Dr. Pedro González de Velasco", Trabajos de la Cátedra de Historia Crítica de la Medicina, VII, pp. 141-151.

Ortiz García, C. y Sánchez Gómez, L. Á. (eds.) (1994), Diccionario histórico de la antropología española, Madrid, Consejo Superior de Investigaciones Científicas.

Perera y Prats, Arturo (1967), "La vida del Dr. Velasco, creador de un museo", Anales de la Real Academia Nacional de Medicina, 84, pp. 351-370.

Porras Gallo, M. Isabel (2002), “Buscando la renovación de la enseñanza médica en la España decimonónica: La Escuela Teórico-Práctica de Medicina y Cirugía del Hospital General de Madrid y la Escuela Práctica de Medicina y Cirugía de Pedro González de Velasco", Medicina \& Historia, 1, cuarta época [número con artículo único].

Puig-Samper Mulero, Miguel Ángel (1982), “El Doctor Pedro González de Velasco y la antropología española del siglo XIX", Asclepio. Revista de Historia de la Medicina y de la Ciencia, XXXIV, pp. 327-337.
Puig-Samper Mulero, Miguel Ángel y Galera, Andrés (1983), La Antropología española del siglo XIX, Madrid, Consejo Superior de Investigaciones Científicas.

Pulido Fernández, Ángel (1894), El Dr. Velasco. Madrid, Establecimiento Tipográfico de E. Teodoro.

Romero de Tejada, Pilar (1992), Un templo a la ciencia. Historia del Museo Nacional de Etnología. Madrid, Ministerio de Cultura.

Ronzón, Elena (1991), Antropología y Antropologías. Ideas para una historia crítica de la antropología española. El siglo XIX. Oviedo, Pentalfa.

Sánchez Gómez, Luis Ángel (2014), “El Museo Antropológico del doctor Velasco (Anatomía de una obsesión)", Anales del Museo Nacional de Antropología, XVI, pp. 265-297.

Uranga, Evaristo (1973), “Un ilustre anatómico y cirujano con ideas necrofílicas del siglo XIX en Zarauz", Boletín de la Real Sociedad Vascongada de los Amigos del País, XXIX (1-2-3), pp. 375-391.

Valis, Nöel (2011), "Autopsias de lo real: resucitando a los muertos", Asclepio. Revista de Historia de la Medicina y de la Ciencia, LXIII (2), pp. 349-378.

Verde Casanova, Ana M. (1980), "La primera sociedad antropológica de España", I Congreso Español de Antropología. Actas. Vol. II, Barcelona, Universidad de Barcelona, pp. 17-38.

Wolf, Stephanie Alana (2010), "Narratives of Anatomy: Arranging Identity and Regulating Visibility in the Nineteenth Century Anatomical Museum", Undergraduate Honors Theses. Paper 3 (Georgia State University), [en línea], disponible en http://scholarworks.gsu.edu/honors_theses, [consultado el 5 de junio de 2014]. 